From the Sarah Cannon Research Institute, Nashville, TN; Division of Hematology/Oncology, University of North Carolina at Chapel Hill, Chapel Hill; Duke University Medical Center, Durham; GlaxoSmithKline Inc,

Research Triangle Park, NC; and Case Western Reserve University,

Cleveland, $\mathrm{OH}$.

Submitted February 22, 2005; accepted April 25, 2005.

Supported by a grant from

GlaxoSmithKline.

Presented in part at the 40th Annual Meeting of the American Society of Clinical Oncology, New Orleans, LA, June 5-8, 2004.

Terms in blue are defined in the glossary, found at the end of this issue and online at wWw.jco.org.

Authors' disclosures of potential conflicts of interest are found at the end of this article.

Address reprint requests to Howard A. Burris III, The Sarah Cannon Research Institute, 250 25th Avenue N, Suite 110 , Nashville, TN 37203; e-mail: hburris@ tnonc.com.

(c) 2005 by American Society of Clinical Oncology

0732-183X/05/2323-5305/\$20.00

DOI: $10.1200 / J C O .2005 .16 .584$

\title{
Phase I Safety, Pharmacokinetics, and Clinical Activity Study of Lapatinib (GW572016), a Reversible Dual Inhibitor of Epidermal Growth Factor Receptor Tyrosine Kinases, in Heavily Pretreated Patients With Metastatic Carcinomas
}

Howard A. Burris III, Herbert I. Hurwitz, E. Claire Dees, Afshin Dowlati, Kimberly L. Blackwell, Bert O'Neil, Paul K. Marcom, Matthew J. Ellis, Beth Overmoyer, Suzanne F. Jones, Jennifer L. Harris, Deborah A. Smith, Kevin M. Koch, Andrew Stead, Steve Mangum, and Neil L. Spector

$$
\begin{array}{llllllll}
\text { A } & \text { B } & \text { S } & \text { T } & \text { R } & \text { A } & \text { C } & \text { T }
\end{array}
$$

\section{Purpose}

This study (EGF10004) assessed the safety/tolerability, pharmacokinetics, and clinical activity of daily oral dosing with lapatinib (GW572016) in patients with ErbB1-expressing and/or ErbB2-overexpressing advanced-stage refractory solid tumors.

\section{Patients and Methods}

Heavily pretreated patients with ErbB1-expressing and/or ErbB2-overexpressing metastatic cancers were randomly assigned to one of five dose cohorts of lapatinib administered once daily. Pharmacokinetic samples were obtained on days 1 and 20. Clinical response was assessed every 8 weeks.

\section{Results}

Sixty-seven patients with metastatic solid tumors were treated with lapatinib. The most frequently reported drug-related adverse events were diarrhea (42\%) and rash (31\%). No grade 4 drug-related adverse events were reported. Five grade 3 drug-related toxicities (gastrointestinal events and rash) were experienced by four patients. Drug-related interstitial pneumonitis or cardiac dysfunction associated with other ErbB-targeted therapies was not reported. Four patients with trastuzumab-resistant metastatic breast cancer-two of whom were classified as having inflammatory breast cancer-had partial responses (PRs). Twenty-four patients with various other carcinomas experienced stable disease, of whom 10 received lapatinib for $\geq 6$ months. The relationships between lapatinib dose or serum concentration and clinical response could not be adequately characterized due to the limited response data. The incidence of diarrhea increased with increasing dose, whereas the incidence of rash was not related to dose.

\section{Conclusion}

Lapatinib was well tolerated at doses ranging from 500 to 1,600 mg once daily. Clinical activity was observed in heavily pretreated patients with ErbB1-expressing and/or ErbB2-overexpressing metastatic cancers, including four PRs in patients with trastuzumab-resistant breast cancers and prolonged stable disease in 10 patients.

\section{J Clin Oncol 23:5305-5313. (C) 2005 by American Society of Clinical Oncology}

\section{INTRODUCTION}

In humans, the ErbB family of transmembrane tyrosine kinase receptors consists of four members: ErbB1 (epidermal growth factor receptor $[\mathrm{EGFR}])$, ErbB2, ErbB3, and ErbB4. ${ }^{1,2}$ Expression of ErbB1 and/or overexpression of ErbB2 occur to varying degrees in epithelial malignancies, where they promote tumor cell growth/survival, and in certain tumors predict for a poor clinical outcome. ${ }^{3-6}$ Upon ligand binding, ErbB receptors form hetero- or homodimers 
resulting in the autophosphorylation of specific tyrosine residues within the conserved catalytic kinase domains of ErbB receptors. ${ }^{1,7}$ These phosphorylated tyrosine residues serve as docking sites for Src-homology 2 and phosphotyrosine-binding domain-containing proteins that link activated ErbB receptors to downstream cell proliferation (mitogen-activated protein kinase [MAPK]) and survival (phosphotidylinositol-3-kinase [PI3K]) pathways. ${ }^{1,2,7-12}$ The established role of ErbB1 and ErbB2 in promoting the growth and survival of various types of solid tumors makes them attractive therapeutic targets. Monoclonal antibodies such as cetuximab and trastuzumab targeting ErbB1 and ErbB2, respectively, as well as smallmolecule tyrosine kinase inhibitors of ErbB1 (eg, gefitinib and erlotinib) have been shown to inhibit proliferation of ErbB1- or ErbB2-expressing cancer cells. ${ }^{13-17}$ Moreover, clinical studies have demonstrated the activity of these ErbB-targeted agents in patients with advanced stage malignancies. ${ }^{18-22}$

Lapatinib (GW572016) is an orally active small molecule that reversibly inhibits ErbB1 and ErbB2 tyrosine kinases, leading to inhibition of MAPK and PI3K signaling in ErbB1-expressing and ErbB2-overexpressing tumor cell lines and xenografts. ${ }^{23,24}$ Lapatinib-treated tumor cells undergo apoptosis or growth arrest depending upon the cell type. ${ }^{23,24}$ ErbB2, the only member of the ErbB family without an exogenous ligand, is the preferred heterodimer partner for other ErbB receptors where it amplifies the biologic signal. ${ }^{1,7}$ Since ErbB2-containing heterodimers exert potent growth and survival effects, simultaneous inhibition of ErbB2 and ErbB1 is an appealing therapeutic strategy.

In phase I studies in healthy volunteers, lapatinib was well tolerated at repeat doses up to the highest dose administered $(175 \mathrm{mg} / \mathrm{d}){ }^{25}$ In the first phase I dose escalation study in cancer patients (EGF10003), lapatinib was well tolerated at doses up to the highest dose administered (1,800 mg once daily) with mild and transient diarrhea, nausea, rash, fatigue, anorexia, and vomiting as the predominant toxicities. ${ }^{26}$ Clinical activity was observed at doses of $650 \mathrm{mg} /$ day and higher. ${ }^{26}$

Pharmacokinetic data from these studies indicated that serum lapatinib concentrations peak 4 hours after dosing, increase with increasing dose, accumulate approximately two-fold with daily dosing, and achieve steady state in 6 to 7 days, suggesting an effective half-life of 24 hours.

This study (EGF10004) was designed to (1) assess the safety and tolerability of lapatinib after multiple dosing; (2) assess the pharmacokinetics of lapatinib; (3) evaluate the biologic effects of lapatinib in serial tumor biopsies; (4) determine a biologically active dose range for lapatinib; and (5) assess the clinical activity of lapatinib. The biologic effects of lapatinib on signaling pathways in tumor tissue obtained from a subset of 33 patients participating in this study who had sequential biopsies were recently re- ported. ${ }^{27}$ The safety/tolerability, pharmacokinetics, and clinical activity of lapatinib are reported here.

\section{PATIENTS AND METHODS}

\section{Eligibility Criteria}

Patients enrolled in this study were males or females age 18 years or older with a histologically-confirmed diagnosis of cancer; had an archived or fresh biopsy that demonstrated expression of ErbB1 (positive by immunohistochemistry [IHC]) and/or overexpression of ErbB2 $(2+$ or $3+$ by IHC) or that displayed gene amplification of ErbB2 by fluorescence in situ hybridization; had a Karnofsky performance status $\geq 70 \%$; had a life expectancy of at least 12 weeks; had a hemoglobin concentration $\geq 9 \mathrm{~g} / \mathrm{dL}$ (5 mmol/L), an absolute granulocyte count $\geq 1,500 / \mathrm{mm}^{3}$ $\left(1.5 \times 10^{9} / \mathrm{L}\right)$, a platelet count $\geq 100,000 / \mathrm{mm}^{3}\left(100 \times 10^{9} / \mathrm{L}\right)$; and were able to swallow and retain oral medication. Patients were excluded from the study if they were pregnant or lactating females; had malabsorption syndrome; received any chemotherapy within the previous 4 weeks or treatment with nitrosourea or mitomycin within the previous 6 weeks; received biologic, hormonal, or radiation therapy within the previous 4 weeks; were taking steroids; had a total bilirubin $>2 \mathrm{mg} / \mathrm{dL}$; had AST or ALT $>$ $3 \times$ the upper limit of normal; had a class III or IV heart failure as defined by the New York Heart Association functional classification system; or had a left ventricular ejection fraction (LVEF) $<$ $40 \%$. All patients provided a signed informed consent.

The study protocol was approved by institutional review boards at the following institutions: TriStar Nashville Market, Nashville, TN; Duke University Health System, Durham; University of North Carolina School of Medicine, Chapel Hill, NC; and University Hospitals of Cleveland, Cleveland, $\mathrm{OH}$. The study was conducted in accordance with the 1996 version of the Declaration of Helsinki.

\section{Safety Assessments}

Patients underwent a physical examination, vital sign measurements, Karnofsky performance status, basic ophthalmologic examination, 12-lead ECG, multigated angiogram (MUGA) scan, hematology, clinical chemistry, and urinalysis performed within 14 days before the first dose of study drug. Physical examination, vital signs, and safety laboratory evaluations were repeated on days 1 and 20. Adverse events (AEs) were graded using the National Cancer Institute Common Toxicity Criteria version 2.0. Patients who continued therapy after Day 21 had safety assessments performed every 4 weeks. ECG and MUGA scans were repeated every 8 weeks during treatment. A poststudy evaluation was required 28 days after the last dose of lapatinib was administered.

\section{Study Treatments}

This was a randomized, parallel-group, repeated doseranging study in patients with solid tumors. Lapatinib (GlaxoSmithKline, Research Triangle Park, NC) was supplied as 100-mg and 250-mg tablets for daily oral administration. Sixty-seven patients were randomly assigned to receive one of five oral doses of lapatinib administered daily for 21 days. The doses administered were chosen on the basis of safety, tolerability, and pharmacokinetic data from prior healthy volunteer ${ }^{25}$ and cancer patient ${ }^{26}$ studies, and included 500, 650, 900, 1,200, and $1,600 \mathrm{mg}$ of lapatinib. The protocol allowed investigator discretion in making upward dose adjustments in patients who were 
assessed as having progressive disease. An amendment was written, but not fully implemented, that included two additional dose groups of 1,000 and 2,000 mg of lapatinib administered daily. After completing the initial 21-day portion of the study, patients continued on once-daily lapatinib therapy until disease progression, treatment-emergent toxicities, or withdrawal of consent.

\section{Pharmacokinetic Assessments}

Blood samples were taken for determination of serum lapatinib concentration on days 1 and 20 before dosing, and at $0.5,0.75$, $1,1.5,2,2.5,3,4,6,8,10,12,16$, and 24 hours after dosing. Serum was separated and stored at $-20^{\circ} \mathrm{C}$ until analysis. Concentrations of lapatinib were measured by liquid chromatography tandem mass spectrometry with parallel online turbulent flow extraction and positive ion selected reaction monitoring, as previously described. $^{28}$ The calibration range of the lapatinib assay was 1 to $1,000 \mathrm{ng} / \mathrm{mL}$. Interassay precision was within $12 \%$, and interassay accuracy was within $8 \%$ of nominal. Pharmacokinetic analyses were performed using WinNonlin 3.2 software (Pharsight, Mountain View, CA). Standard noncompartmental methods were used to calculate area under the serum concentration versus time curve within the dosing interval $\left(\mathrm{AUC}_{\tau}\right)$, peak serum concentration $\left(\mathrm{C}_{\max }\right)$, the time at which $\mathrm{C}_{\max }$ occurred $\left(\mathrm{t}_{\max }\right)$ on days 1 and 20 , and steady-state trough concentration $\left(\mathrm{C}_{\min }\right)$ on day 20.

\section{Evaluation of Clinical Activity}

Disease status was assessed predose, after 8 weeks of therapy, and every 8 weeks thereafter until withdrawal from the study using the Response Evaluation Criteria in Solid Tumors (RECIST) Guidelines. ${ }^{29}$ Patients who did not have lesions that were assessable by RECIST (eg, dermatologic changes consistent with inflammatory breast cancer) were evaluated by clinical assessment.

\section{RESULTS}

\section{Patient Characteristics}

Sixty-seven patients were enrolled at four sites in the United States between March 2002 and May 2003. Patients were randomly assigned to one of five daily dose cohorts (500 mg [ $\mathrm{n}=13], 650 \mathrm{mg}[\mathrm{n}=15], 900 \mathrm{mg}[\mathrm{n}=11]$, $1,200 \mathrm{mg}[\mathrm{n}=12]$, and $1,600 \mathrm{mg}[\mathrm{n}=13])$, with the later addition of a cohort at $1,000 \mathrm{mg}$ daily $(\mathrm{n}=3)$. Patient characteristics are shown in Table 1 . The study population included patients with a variety of solid tumors, with breast cancer being the most common $(\mathrm{n}=30)$. The patient population was heavily pretreated, with 66 patients (99\%) having received previous chemotherapy. These

\begin{tabular}{|c|c|c|c|c|c|c|}
\hline \multirow[b]{2}{*}{ Characteristic } & \multicolumn{6}{|c|}{ No. of Patients } \\
\hline & $\begin{array}{l}500 \\
\mathrm{mg}\end{array}$ & $\begin{array}{l}650 \\
\mathrm{mg}\end{array}$ & $\begin{array}{c}900 \\
\mathrm{mg}\end{array}$ & $\begin{array}{c}1,000 \\
\mathrm{mg}\end{array}$ & $\begin{array}{c}1,200 \\
\mathrm{mg}\end{array}$ & $\begin{array}{c}1,600 \\
\mathrm{mg}\end{array}$ \\
\hline \multicolumn{7}{|l|}{ Sex } \\
\hline Male & 3 & 4 & 4 & 0 & 3 & 4 \\
\hline Female & 10 & 11 & 7 & 3 & 9 & 9 \\
\hline \multicolumn{7}{|l|}{ Age, years } \\
\hline Median & 56 & 60 & 57 & 53 & 54 & 55 \\
\hline Range & $28-74$ & $37-82$ & $34-82$ & $43-59$ & $37-67$ & $38-70$ \\
\hline \multicolumn{7}{|l|}{ Prior treatments } \\
\hline Median & 6 & 7 & 5 & 6 & 4 & 5 \\
\hline Range & $2-10$ & $1-11$ & $1-13$ & $0-9$ & $1-14$ & $2-10$ \\
\hline \multicolumn{7}{|l|}{ Disease site } \\
\hline Breast & 6 & 6 & 5 & 3 & 6 & 4 \\
\hline AUP & 1 & 1 & 2 & 0 & 0 & 1 \\
\hline CRC & 2 & 2 & 1 & 0 & 1 & 1 \\
\hline $\mathrm{H} \& N$ & 0 & 1 & 0 & 0 & 2 & 2 \\
\hline Ovarian & 1 & 1 & 1 & 0 & 0 & 1 \\
\hline Lung & 1 & 2 & 2 & 0 & 2 & 3 \\
\hline Other & 2 & 0 & 0 & 0 & 1 & 1 \\
\hline
\end{tabular}

Abbreviations: AUP, adenocarcinoma of unknown primary origin; $\mathrm{CRC}$, colorectal cancer; H\&N, head and neck carcinoma.

patients received a median of five prior therapies with a range of one to 14 .

\section{Safety and Tolerability}

Forty-four (66\%) of 67 patients experienced drugrelated AEs. The most frequently reported drug-related AEs were diarrhea (42\%) and rash (31\%) (Table 2). Other drug-related AEs included nausea (13\%) and fatigue (10\%); all remaining drug-related AEs occurred with an incidence of $5 \%$ or less. Most drug-related AEs (135 of 140 ) were mild in intensity (grade 1 or 2). Five grade 3 AEs experienced by four patients were considered to be drug-related: one patient had grade 3 abdominal pain at the 650-mg dose level, one patient had grade 3 rash and grade 3 diarrhea at the 1,000-mg dose level that required a dose reduction to $500 \mathrm{mg}$; one patient had grade $3 \mathrm{di}$ arrhea at the 1,200-mg dose level that required temporary interruption of lapatinib (the patient continued to experience grade 2 diarrhea at a reduced dose of $650 \mathrm{mg}$ and was subsequently withdrawn); one patient who initially received $900 \mathrm{mg}$ and subsequently received 1,600 mg lapatinib was withdrawn due to grade 3 gastroesophageal reflux disease. The gastrointestinal reflux was believed by the investigator to be related to the large pill burden.

\begin{tabular}{|c|c|c|c|c|c|c|c|c|}
\hline \multirow[b]{2}{*}{ Adverse Event } & \multicolumn{6}{|c|}{ Dose $(\mathrm{mg})^{*}$} & \multicolumn{2}{|r|}{$N=67$} \\
\hline & $500(n=13)$ & $650(n=15)$ & $900(n=11)$ & $1,000(n=3)$ & $1,200(n=12)$ & $1,600(n=13)$ & Total & Grade 3 events $\dagger$ \\
\hline Diarrhea & 4 & 5 & 3 & 2 & 5 & 9 & 28 & 2 \\
\hline Rash & 5 & 5 & 3 & 3 & 2 & 3 & 21 & 1 \\
\hline Nausea & 1 & 3 & 2 & 1 & 1 & 1 & 9 & 0 \\
\hline Fatigue & 0 & 2 & 2 & 1 & 1 & 1 & 7 & 0 \\
\hline
\end{tabular}


No grade 4 drug-related AEs were reported. No additional temporary treatment interruptions, dose-reductions, or withdrawals were associated with drug-related AEs.

Drug-related rash (rash, acne, dermatitis acneiform) was reported in $21(31 \%)$ of 67 patients and was generally mild or moderate (grade 1 or 2 ) in intensity; only one grade 3 rash was reported (as described in the preceding paragraph). In most patients, the onset of rash occurred between days 2 and 66 and generally resolved without interrupting treatment. Five patients with one or more drug-related skin rash AEs received treatment with dermatologic medications without resolution. The rash remained unresolved at the time of study termination in three patients who did not receive dermatologic medications.

No significant drug-related reductions in LVEF or drug-related occurrences of interstitial pneumonitis were reported; one patient experienced an asymptomatic decrease in LVEF from $37 \%$ at baseline to $20 \%$ on day 140 , which was reported to be related to underlying disease and cor pulmonale rather than lapatinib. The patient, who was granted a protocol exception at screening for LVEF $\leq 40 \%$, continued treatment without interruption until disease progression. The LVEF value returned to near baseline by the time of study termination. Few changes in clinical laboratory values were reported as AEs during the study, and most of these laboratory changes were not related to lapatinib. Three patients had grade 1 anemia at the 500-, 900-, and 1,600-mg dose levels that was considered to be drug-related. Grade 1 anemia resolved on the same day as onset in one patient $(900 \mathrm{mg}$ ), 5 days after onset in the second patient $(500 \mathrm{mg})$, and remained unresolved in the third patient $(1,600 \mathrm{mg})$. No clinically significant changes in vital sign measurements or ECG results were observed at any dose level, and no patient had ophthalmologic abnormalities.

Only one of 53 serious AEs (grade 2 diarrhea at the 650-mg dose level) was considered to be related to lapatinib. The remainder of the serious AEs were due to hospitalizations for events related to disease progression. There were seven deaths during the study, but none was considered drug-related.

\section{Clinical Activity}

Fifty-nine of 67 patients were assessable for disease assessment. Four patients experienced partial responses. All four had breast cancer, overexpressed ErbB2 (3+ by IHC), and with one exception, co-expressed ErbB1. Two of the partial responders had recurrent inflammatory breast cancer, based on clinical history and evidence of dermallymphatic invasion on histopathology (Fig 1A). The patients who achieved partial responses (PRs) also had high expression of activated, phosphorylated ErbB2 that was inhibited with lapatinib therapy (Fig $1 \mathrm{~B}$ and $1 \mathrm{C}$ ). Detailed analysis of the biologic effects of lapatinib in this
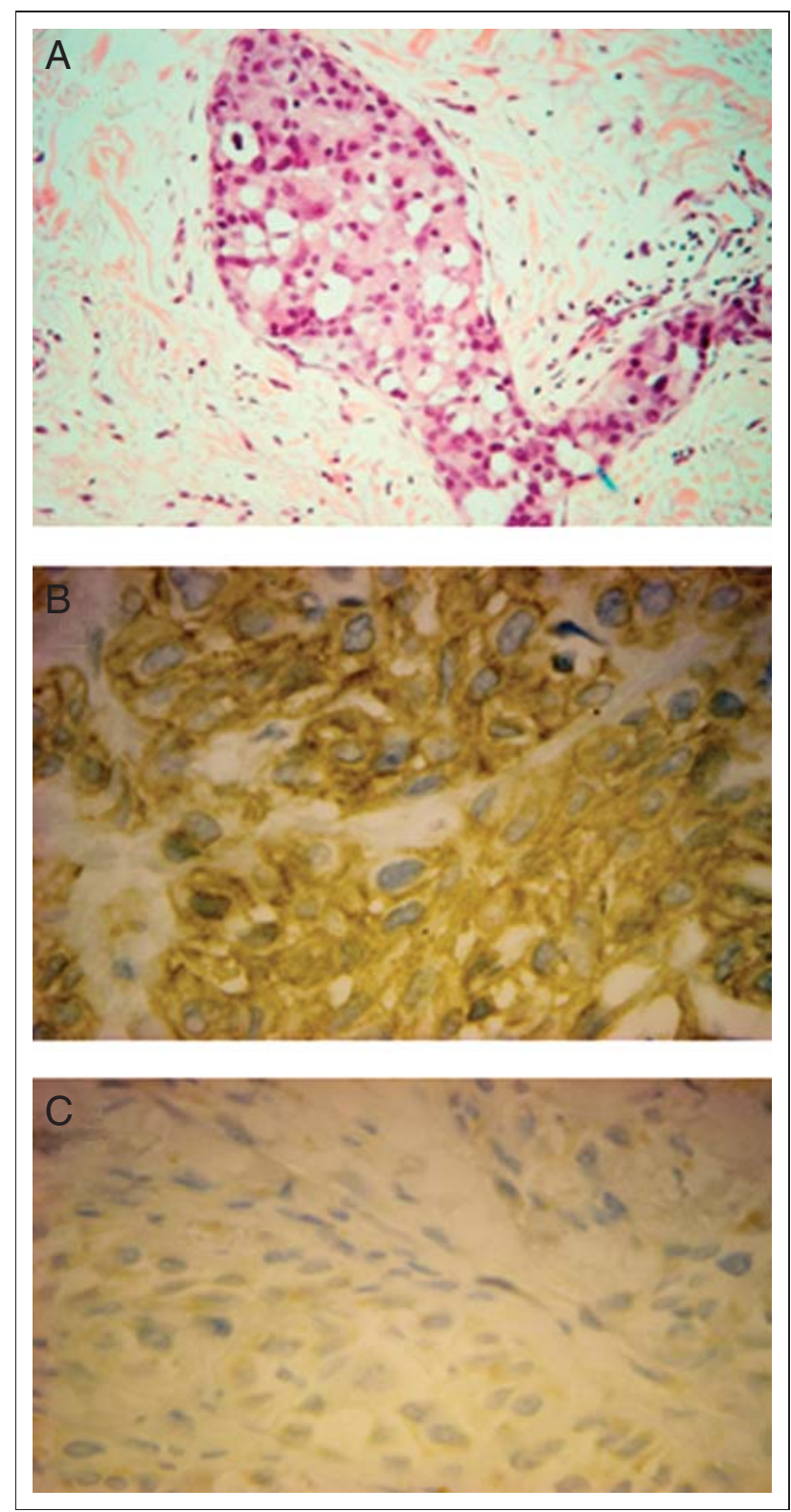

Fig 1. Representative histopathology and inhibition of activated, phosphorylated ErbB2 (p-ErbB2) in a responding patient with breast cancer. (A) Histopathology demonstrates dermal-lymphatic invasion consistent with recurrent inflammatory breast cancer. Immunohistochemistry staining of p-ErbB2 was performed from tumor biopsies on days 0 (B) and 21 (C) of lapatinib therapy. ${ }^{27}$

study (EGF10004) was described recently. ${ }^{27}$ Figure 2 demonstrates the clinical regression observed in one patient with recurrent advanced stage inflammatory breast cancer. All four partial responders were previously treated with trastuzumab, either alone or in combination with multiple chemotherapeutic regimens (eg, anthracycline and/or taxane based). The median duration of treatment for patients with PR was 5.5 months (range, 3 to 8 months). Stable disease (SD) was reported in 24 patients ( 10 breast cancer, five non-small-cell lung cancer (NSCLC), three colorectal cancer, 


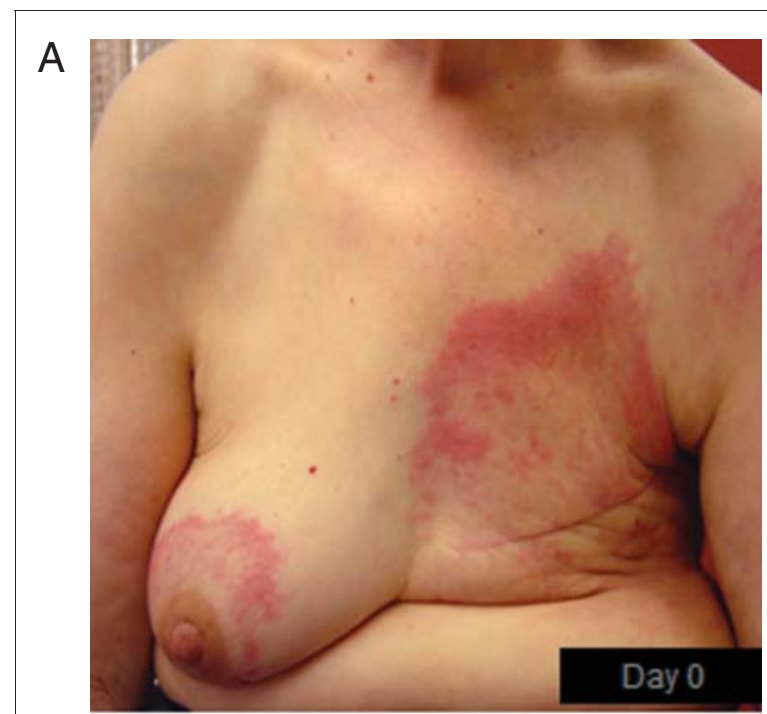

B

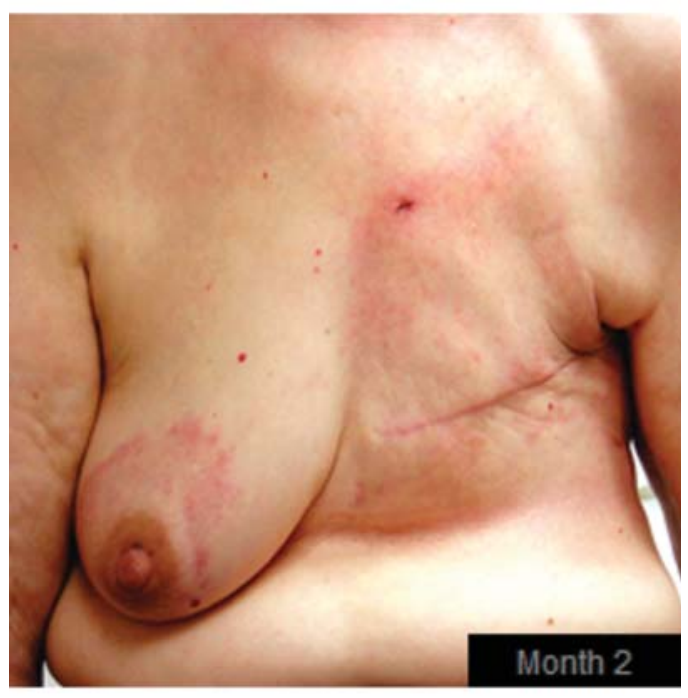

C

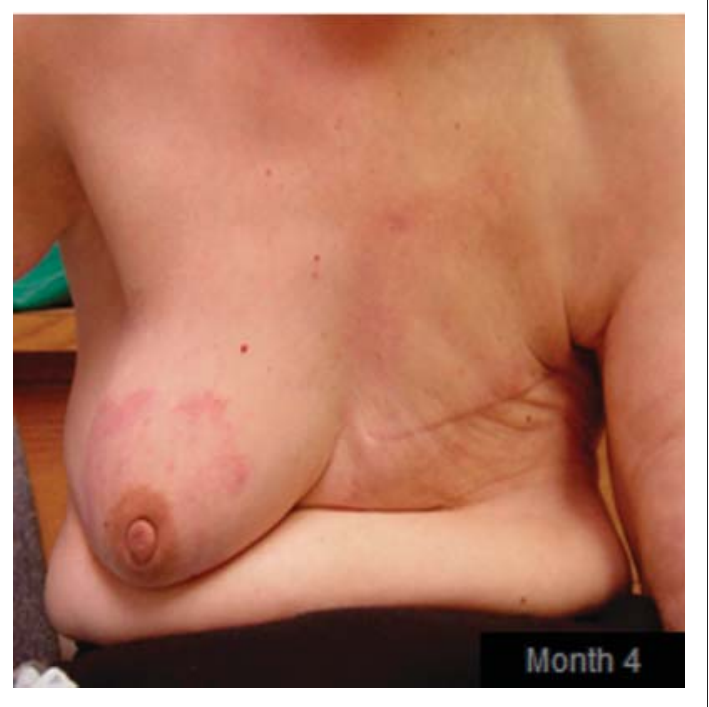

Fig 2. Clinical regression of breast cancer in a patient achieving a partial response comparing day $0(A)$ with $2(B)$ and $4(C)$ months on lapatinib therapy. three head and neck cancer, one ovarian cancer, one adenocarcinoma of unknown primary, and one granular cell carcinoma). Twenty-two of 28 patients who achieved either PR or SD received lapatinib treatment for $\geq 3$ months, and 12 of these patients received treatment for $\geq 6$ months, including six patients with breast cancer, two with NSCLC, three with head and neck cancer, and one with colorectal cancer (Table 3). Four patients received lapatinib treatment for more than 1 year, including a 62-year-old man with colorectal cancer who received lapatinib for 15 months; a 55-year-old woman with NSCLC who received lapatinib for 12 months; a 44-yearold man with head and neck cancer who received lapatinib for 21 months; and a 69-year-old woman with NSCLC who received lapatinib for 18 months.

Before discontinuing therapy, the protocol allowed investigator discretion for intrapatient dose escalation in patients who were assessed as having progressive disease. However, there was no instance in which this resulted in an objective clinical response. At the investigators' discretion, doses were increased after 1 to 3 months of treatment in four patients with SD who continued with SD for an additional 6 to 10 months.

\section{Pharmacokinetics}

Median steady-state (day 20) serum concentration profiles at each dose are shown in Figure 3. Serum concentrations peaked on average 3 to 6 hours postdose, and repeated dosing resulted in an approximately two-fold accumulation on day 20 relative to day 1 (data not shown). Steady-state $\mathrm{AUC}_{\tau}, \mathrm{C}_{\max }$, and $\mathrm{C}_{\min }$ at each dose are summarized in Table 4. Serum concentrations generally increased with increasing dose, although variability was high. Concentrations at the 1,200-mg dose were a notable exception, resembling those at the $500 \mathrm{mg}$ and $650 \mathrm{mg}$ doses rather than falling between those at $900 \mathrm{mg}$ and 1,600 mg.

\begin{tabular}{|c|c|c|c|}
\hline $\begin{array}{l}\text { Dose Level } \\
\text { (mg) }\end{array}$ & $\begin{array}{l}\text { Tumor } \\
\text { Type }\end{array}$ & Response* & $\begin{array}{c}\text { Duration on } \\
\text { Lapatinib (months) }\end{array}$ \\
\hline 650 & Breast & PR & 8 \\
\hline 1,200 & Breast & PR & 6 \\
\hline 900 & Breast & PR & 6 \\
\hline 1,200 & Head and Neck & SD & 21 \\
\hline 1,600 & NSCLC & SD & 18 \\
\hline 900 & Colorectal & SD & 15 \\
\hline 900 & NSCLC & SD & 12 \\
\hline 500 & Breast & SD & 9.5 \\
\hline 500 & Head and Neck & SD & 9.5 \\
\hline 500 & Breast & SD & 7 \\
\hline 1,200 & Breast & SD & 6 \\
\hline 1,200 & Head and Neck & SD & 6 \\
\hline \multicolumn{4}{|c|}{$\begin{array}{l}\text { *Response was summarized by the dose to which the patient was } \\
\text { initially assigned. Dose adjustments were permitted; therefore, patients } \\
\text { in the lower dose groups may also have received higher doses of } \\
\text { lapatinib during the course of their treatment. } \\
\text { Abbreviations: PR, partial response; SD, stable disease; NSCLC, non- } \\
\text { small-cell lung cancer. }\end{array}$} \\
\hline
\end{tabular}




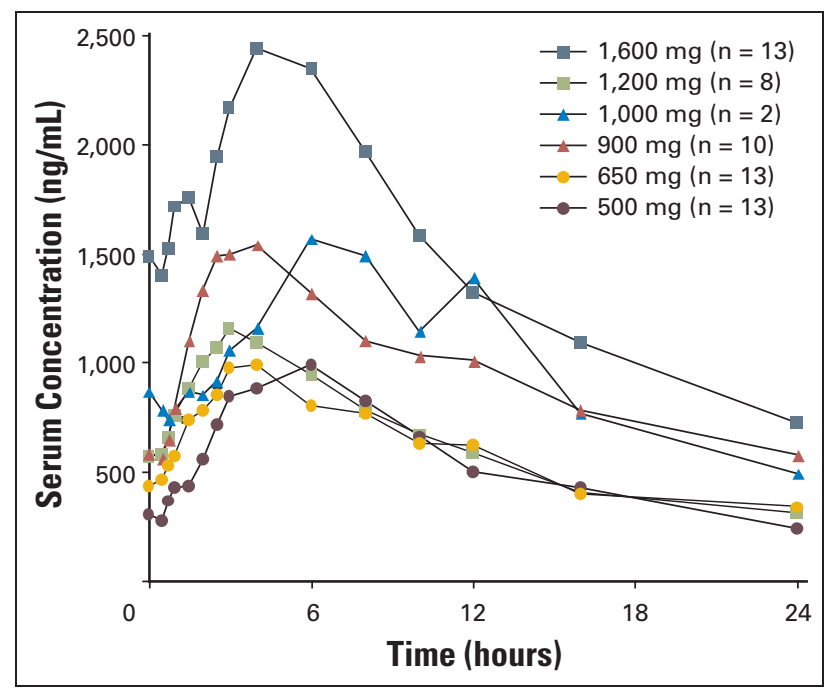

Fig 3. Median steady-state serum concentration profiles at each daily dose of lapatinib.

\section{Dose and Concentration Relationships With Response and Toxicity}

The frequency of clinical response, categorized as PR, $\mathrm{SD}>6$ months, or nonresponders, was examined in relation to drug exposure, in terms of dose, and steady-state AUC, $C_{\max }$, and $\mathrm{C}_{\min }$. The relationship with dose (Fig 4) indicates that the majority of responders ( $\mathrm{PR}$ and $\mathrm{SD}>6$ months) were receiving 1,200 $\mathrm{mg}$ daily (median dose in all responders). The relationship with $C_{\min }$ (Fig 5), which demonstrated a right-skewed distribution, indicates that the majority of responders displayed a trough concentration in the 0.3 to $0.6 \mu \mathrm{g} / \mathrm{mL}$ range. The median dose in all patients, as well as responders only, which produced a $\mathrm{C}_{\min }$ in this range was $900 \mathrm{mg}$ daily. Similar relationships were observed with $\mathrm{AUC}_{\tau}$ and $\mathrm{C}_{\max }$ (data not shown).

Regression analysis suggested that the frequency of diarrhea was linearly related to dose $(P<.03)$ over the 500 to $1,600 \mathrm{mg}$ range. There was no apparent relationship of diarrhea to serum concentration. The incidence of rash showed no apparent relationship to dose or serum concentration, or to clinical response as described for other EGFR inhibitors. Figure 6 shows the incidence of clinical response in relation to lapatinib dose categorized by oc-

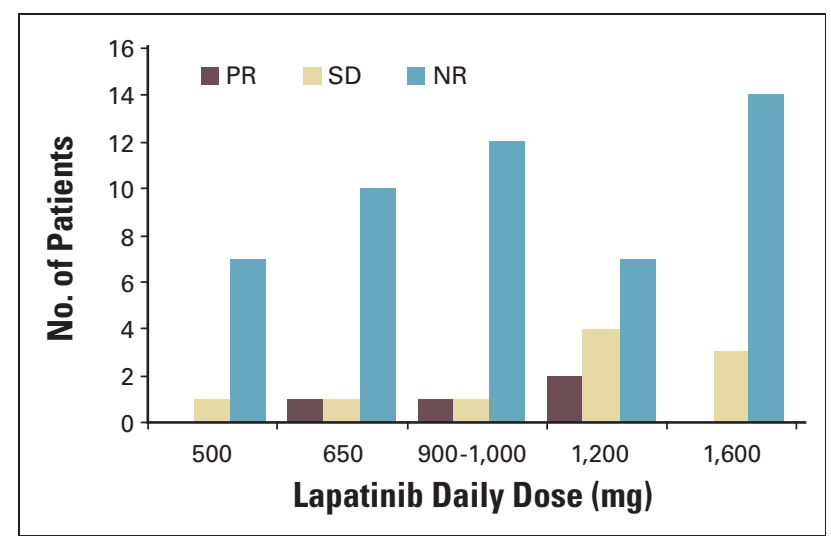

Fig 4. Clinical response in relation to lapatinib dose. PR, partial response; $\mathrm{SD}$, stable disease $>6$ months; NR, nonresponders.

currence of rash. The number of responders (PR and $\mathrm{SD}>6$ months either alone or combined) was larger without rash compared to those with rash, demonstrating that rash is not an indicator of clinical response to lapatinib.

\section{DISCUSSION}

Lapatinib was well tolerated in this study at doses up to $1600 \mathrm{mg}$ daily with clinical activity observed at doses ranging from 650 to $1,600 \mathrm{mg}$ daily in heavily pretreated patients with ErbB1-expressing and/or ErbB2-overexpressing metastatic solid tumors. At doses where clinical activity was observed, drug-related toxicity was primarily restricted to grade 1 and 2 diarrhea (42\%) and skin rash (31\%). No grade 4 toxicity was reported.

Four patients with advanced-stage breast cancer whose disease had progressed on prior trastuzumab and taxane- or anthracycline-based chemotherapy regimens, achieved a PR with lapatinib. All of these patients had tumors that overexpressed ErbB2, and with the one exception, co-expressed ErbB1. ${ }^{27}$ In addition, these four patients exhibited baseline expression of activated, phosphorylated ErbB2 that was increased compared with nonresponders ( Fig 1$).{ }^{27}$ Anadditional 24 patients experienced disease stabilization. Twelve of 28 patients with either a PR or SD received lapatinib for $\geq 6$ months and four patients (NSCLC [ $=2]$, colorectal, head and neck) received lapatinib therapy for more than 1 year.

\begin{tabular}{|c|c|c|c|c|c|c|}
\hline \multirow[b]{2}{*}{ Daily Dose (mg) } & \multicolumn{2}{|c|}{$\mathrm{AUC}_{\tau}(\mathrm{h} \cdot \mu \mathrm{g} / \mathrm{mL})$} & \multicolumn{2}{|c|}{$\mathrm{C}_{\max }(\mu \mathrm{g} / \mathrm{mL})$} & \multicolumn{2}{|c|}{$\mathrm{C}_{\min }(\mu \mathrm{g} / \mathrm{mL})$} \\
\hline & Geometric Mean & $95 \% \mathrm{Cl}$ & Geometric Mean & $95 \% \mathrm{Cl}$ & Geometric Mean & $95 \% \mathrm{Cl}$ \\
\hline 500 & 13.9 & 9.94 to 19.6 & 1.02 & 0.76 to 1.38 & 0.28 & 0.18 to 0.43 \\
\hline 650 & 15.7 & 11.9 to 20.8 & 1.30 & 0.98 to 1.72 & 0.35 & 0.24 to 0.50 \\
\hline 900 & 23.3 & 16.3 to 33.4 & 1.70 & 1.21 to 2.40 & 0.57 & 0.35 to 0.92 \\
\hline 1,000 & 23.6 & 20.6 to 27.1 & 1.85 & 1.40 to 2.45 & 0.49 & 0.05 to 5.23 \\
\hline 1,200 & 14.3 & 9.42 to 21.8 & 1.22 & 0.90 to 1.65 & 0.30 & 0.19 to 0.48 \\
\hline 1,600 & 29.4 & 15.9 to 54.3 & 2.13 & 1.36 to 3.35 & 0.64 & 0.28 to 1.49 \\
\hline
\end{tabular}




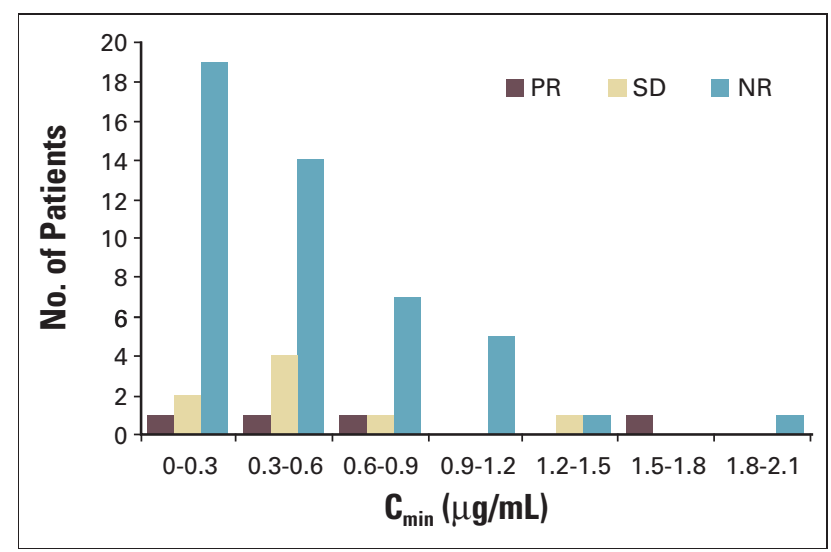

Fig 5. Clinical response in relation to lapatinib steady-state concentration. PR, partial response; SD, stable disease $>6$ months; NR, nonresponders; $\mathrm{C}_{\text {min }}$, steady-state trough concentration.

Further evidence for the clinical activity of lapatinib in heavily pretreated patients with advanced solid tumors was presented in two studies. ${ }^{26,30}$ Minami et $\mathrm{al}^{30}$ reported that two patients had PR: one with breast cancer treated with lapatinib 1,600 mg once daily, and the other with squamous cell carcinoma of the lung treated with lapatinib $900 \mathrm{mg}$ once daily. Twelve patients (NSCLC [ $=6]$, colorectal cancer $[n=3]$, breast cancer $[n=1]$, cervical cancer $[n=1]$, ovarian cancer $[\mathrm{n}=1]$ ) had SD and eight of 14 patients with clinical activity remained on lapatinib therapy for more than 3 months. Versola et $\mathrm{al}^{26}$ reported a CR in a patient with an ErbB1-overexpressing head and neck squamous cell carcinoma. Twenty-two patients with various tumors, most expressing either ErbB1 or ErbB2, experienced SD with a median duration of 4 months (range $1-13+$ months). ${ }^{26}$ Together, these studies indicate the potential clinical activity of lapatinib in patients with a variety of solid tumors.

The pharmacokinetics of lapatinib upon repeated dosing display a time-dependent increase in systemic exposure as described previously. ${ }^{25}$ For this reason, half-lives and areas under the curve (AUCs) after a single or first dose do not predict accumulation or steady-state concentration,

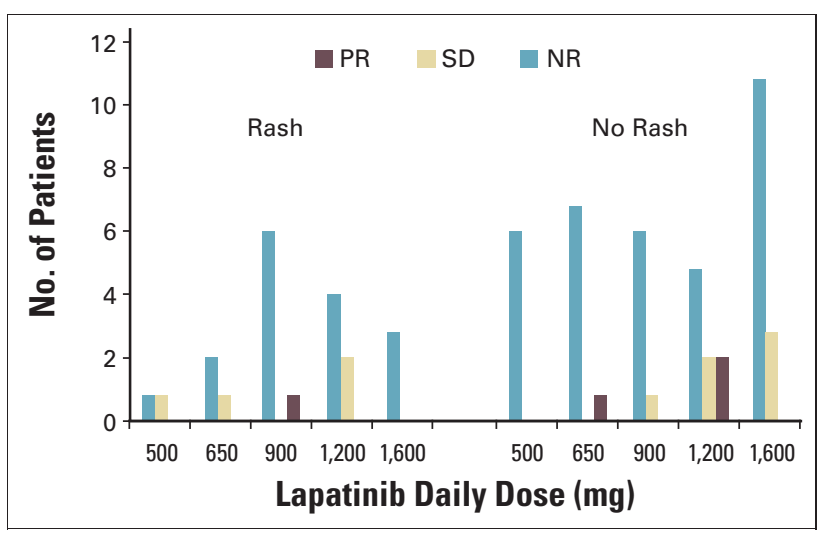

Fig 6. Clinical response in relation to lapatinib dose categorized by occurrence of rash. PR, partial response; SD, stable disease $>6$ months; NR, nonresponders. which represents the therapeutically relevant systemic exposure for this chronic therapy. The pharmacokinetics of lapatinib in this study were, on average, similar, but exhibited greater variability than in previous studies of either healthy volunteers or cancer patients. ${ }^{25,31}$ This difference may be secondary to allowing consumption of food with the doses on days 2 through 19 or the effect of concurrent medications required by patients that could alter the absorption and/or metabolism of lapatinib. Absorption of lapatinib is restricted by low solubility and first-pass metabolism by CYP3A4/5, which likely contribute to the variability in systemic exposure. Transporters may also be involved, although lapatinib does not appear to be a substrate for P-glycoprotein (ABCB1).

Clinical responses were generally associated with doses in the middle of the range examined in this study. In terms of either the administered dose or the resulting serum concentration, clinical response was more often associated with doses of 900 to $1,200 \mathrm{mg}$ daily. However, due to the limited response data, it was not possible to adequately characterize the relationship between clinical response and drug exposure. In addition, there was no clear distinction between responders (PR and $\mathrm{SD}>6$ months) and nonresponders related to drug exposure, suggesting that the distinction between responders and nonresponders may lie in the inherent biologic profile of the tumor, specifically, which signaling pathways are operative, and which pathways are directly involved in regulating tumor cell growth and survival. If tumor cell survival is dependent upon pathways that can be abrogated by lapatinib, then those tumors might be more likely to respond to therapy. If tumors have developed mechanisms to evade apoptosis, and lapatinib exerts its anti-tumor effects through activation of apoptosis, ${ }^{23,24}$ then those tumors might be resistant to lapatinib therapy. ${ }^{27}$ Current efforts are focused on identifying a tumor profile that will predict for response to lapatinib therapy.

There has been considerable discussion regarding whether skin rash is requisite to achieve clinical response with ErbB1 inhibitors. In this study, the incidence and severity of skin rash was not associated with clinical response (Fig 5) as reported for other small-molecule ErbB inhibitors (eg, gefitinib, erlotinib). This distinction, along with other differences in biochemical and biologic activity, may relate to the unique 4-anilinoquinazoline structure of lapatinib in contrast to either gefitinib or erlotinib, which are quinazolines. ${ }^{32}$

Lapatanib was well tolerated at doses ranging from 500 to $1,600 \mathrm{mg}$ once daily with grade 1 and 2 diarrhea and rash as the most common drug-related toxicities. The association between diarrhea and dose but not concentration suggests that this toxicity evolves from a local effect on the gut epithelium. Similar and more severe toxicities have been reported in studies of other small-molecule ErbB1 tyrosine kinase inhibitors. In phase I studies of gefitinib and erlotinib, 
both reversible inhibitors of ErbB1, the most frequently reported AEs were nausea, vomiting, acneiform rash, and diarrhea in patients treated with gefitinib, ${ }^{33}$ and diarrhea, rash, nausea, headache, emesis, and fatigue in patients with treated with erlotinib. ${ }^{34}$ Dose-limiting toxicities of PKI166, a ErbB1 and ErbB2 tyrosine kinase inhibitor, included grade 3 transaminase elevations, skin rash, and diarrhea. ${ }^{35-37}$ Clinical studies of CI-1033, an irreversible pan-ErbB inhibitor, have shown that the most frequently reported AEs were grade 1 to 2 nausea, emesis, diarrhea, acneiform rash, stomatitis, ${ }^{38}$ and asthenia. ${ }^{39}$ In addition, reversible dose-limiting hypersensitivity reactions, ${ }^{38}$ grade 3 thrombocytopenia, ${ }^{40}$ and dose-limiting grade 3 stomatitis have also been reported with CI-1033. ${ }^{41}$

Treatment with trastuzumab has been reported to be associated with an increased incidence of reversible cardiomyopathy. However, it is not known whether this effect is specific to trastuzumab, or a class effect associated with ErbB2 inhibition. ${ }^{42,43}$ No evidence of drug-related cardiac dysfunction was observed in this study.
Clinical activity was observed at lapatinib daily doses ranging from 500 to $1,600 \mathrm{mg}$, and most frequently at 900 to $1,200 \mathrm{mg}$, in heavily pretreated patients with metastatic carcinomas overexpressing ErbB2 and/or expressing ErbB1. Because drug exposure does not appear to distinguish between responders and nonresponders, identification of a tumor profile, based on biologic features, that predicts for response to lapatinib is currently being investigated.

\section{Acknowledgment}

We thank the patients who participated in this study and their families. We thank Terry Paul for his assistance in the preparation of the manuscript, and Lini Pandite and Elaine Paul for their critical review of the manuscript. We also thank the staff at the study centers, in particular, Elizabeth Humes, Henry Bell, Roxanne Williams-Truax, Shawna Savage, Noel Willcutt, Sharon Calvert, and Leslie Kosco, for their diligence in identifying and caring for the patients who participated in the study.

\section{Authors' Disclosures of Potential Conflicts of Interest}

Although all authors completed the disclosure declaration, the following authors or their immediate family members indicated a financial interest. No conflict exists for drugs or devices used in a study if they are not being evaluated as part of the investigation. For a detailed description of the disclosure categories, or for more information about ASCO's conflict of interest policy, please refer to the Author Disclosure Declaration and the Disclosures of Potential Conflicts of Interest section in Information for Contributors.

\begin{tabular}{|c|c|c|c|c|c|c|c|c|}
\hline Authors & Employment & Leadership & Consultant & Stock & Honoraria & Research Funds & Testimony & Other \\
\hline Howard Burris & & & GlaxoSmithKline (A) & & GlaxoSmithKline (A) & & & \\
\hline Herbert Hurwitz & & & $\begin{array}{c}\text { Genentech (B) } \\
\text { GlaxoSmithKline (A) } \\
\text { Pfizer (A) }\end{array}$ & & & $\begin{array}{c}\text { Genentech (B) } \\
\text { Pfizer (B) } \\
\text { GlaxoSmithKline (B) } \\
\text { AstraZeneca (B) } \\
\text { BMS (B) } \\
\text { Sunesis (B) }\end{array}$ & & \\
\hline Claire Dees & & & & & & GlaxoSmithKline (B) & & \\
\hline Kimberly Blackwell & & & & & GlaxoSmithKline (A) & & & \\
\hline Matthew Ellis & & & GlaxoSmithKline (A) & & & & & \\
\hline Beth Overmoyer & & & & & GlaxoSmithKline (A) & & & \\
\hline Suzanne Jones & & & & GlaxoSmithKline (A) & & & & \\
\hline Jennifer Harris & GlaxoSmithKline & & & GlaxoSmithKline (A) & & & & \\
\hline Deborah Smith & GlaxoSmithKline & & & & & & & \\
\hline Kevin Koch & GlaxoSmithKline & & & GlaxoSmithKline (A) & & & & \\
\hline Andrew Stead & GlaxoSmithKline & & & GlaxoSmithKline (B) & & & & \\
\hline Steve Mangum & GlaxoSmithKline & & & GlaxoSmithKline (A) & & & & \\
\hline Neil Spector & GlaxoSmithKline & & & & & & & \\
\hline \multicolumn{9}{|c|}{ Dollar amount codes: } \\
\hline
\end{tabular}

\section{REFERENCES}

1. Yarden $Y$, Sliwkowski MX: Untangling the ErbB signaling network. Nat Rev Mol Cell Biol 2:127-137, 2001
2. Klapper LN, Kirschbaum MH, Sela M, et al: Biochemical and clinical implications of ErbB/HER signaling network of growth factor receptors. Adv Cancer Res 77:25-79, 2000
3. Slamon DJ, Clark GM, Wong SG, et al: Human breast cancer: Correlation of relapse and survival with amplification of the HER-2/neu oncogene. Science 235:177-182, 1987 
4. Slamon D, Godolphin W, Jones LA, et al: Studies of the HER-2/neu proto-oncogene in human breast and ovarian cancer. Science 244 707-712, 1989

5. Bacus SS, Zelnich CR, Plowman G, et al: Expression of the erbB-2 family of growth factor receptors and their ligands in breast cancer: Implication for tumor biology and clinical behavior. Am J Clin Pathol 102:S13-S24, 1994

6. Sainsbury JR, Malcolm AJ, Appleton DR et al: Presence of epidermal growth factor receptors as an indicator of poor prognosis in patients with breast cancer. J Clin Pathol 38 : 1225-1228, 1985

7. Olayioye MA, Graus-Porta $D$, Beerli RR, et al: ErbB-1 and ErbB-2 acquire distinct signaling properties dependent upon their dimerization partner. Mol Cell Biol 18:5042-5051, 1998

8. Ullrich A, Schlessinger J: Signal transduction by receptors with tyrosine kinase activity. Cell 61:203-212, 1990

9. Fukazawa T, Miyake S, Band V, et al: Tyrosine phosphorylation of $\mathrm{Cbl}$ upon epidermal growth factor (EGF) stimulation and its association with EGF receptor and downstream signaling proteins. J Biol Chem 271:14554-14559, 1996

10. Hackel PO, Zwick E, Prenzel N, et al: Epidermal growth factor receptors: Critical mediators of multiple receptor pathways. Curr Opin Cell Biol 11:184-189, 1999

11. Tzahar $E$, Waterman $H$, Chen $X$, et al: $A$ hierarchical network of interreceptor interactions determines signal transduction by Neu differentiation factor/neuregulin and epidermal growth factor. Mol Cell Biol 16:5276-5287, 1996

12. Lange CA, Richer JK, Shen $T$, et al: Convergence of progesterone and epidermal growth factor signaling in breast cancer: Potentiation of mitogen-activated protein kinase pathways. J Biol Chem 273:31308-31316, 1998

13. Moyer JD, Barbacci EG, Iwata KK, et al: Induction of apoptosis and cell cycle arrest by OSI-774, an inhibitor of epidermal growth factor receptor tyrosine kinase. Cancer Res 57:48384848, 1997

14. Moasser MM, Basso A, Averbuch SD, et al: The tyrosine kinase inhibitor ZD1839 ("Iressa") inhibits HER2-driven signaling and suppresses the growth of HER2-overexpressing tumor cells. Cancer Res 61:7184-7188, 2001

15. Hudziak RM, Lewis GD, Winget $M$, et al: $A$ p185 ${ }^{\text {HER2 }}$ monoclonal antibody has antiproliferative effects in vitro and sensitizes human breast tumor cells to tumor necrosis factor. Mol Cell Biol 9:1165-1172, 1989

16. Moulder SL, Yakes FM, Muthuswamy SK, et al: Epidermal growth factor receptor (HER1) tyrosine kinase inhibitor ZD1839 (Iressa) inhibits HER2/neu (erbB2)-overexpressing breast cancer cells in vitro and in vivo. Cancer Res 61:88878895, 2001

17. Ciardiello F, Caputo R, Bianco $R$, et al: Antitumor effect and potentiation of cytotoxic drugs activity in human cancer cells by ZD-1839 (Iressa), an epidermal growth factor receptorselective tyrosine kinase inhibitor. Clin Cancer Res 6:2053-2063, 2000
18. Cobleigh MA, Vogel CL, Tripathy $D$, et al: Multinational study of the efficacy and safety of humanized anti-Her2 monoclonal antibody in women who have Her2-overexpressing metastatic breast cancer that has progressed after chemotherapy for metastatic disease. J Clin Oncol 17:2639-2648, 1999

19. Mendelsohn J, Baselga J: The EGF receptor as targets for cancer therapy. Oncogene 19:6550-6565, 2000

20. Hecht JR, Patnaik A, Malik I, et al: ABX EGF monotherapy in patients (pts) with metastatic colorectal cancer (mCRC): An updated analysis. Proc Am Soc Clin Oncol 23:248, 2004 (abstr 3511)

21. Vanhoefer $U$, Tewes $M$, Rojo $F$, et al: Phase I study of the humanized antiepidermal growth factor receptor monoclonal antibody EMD72000 in patients with advanced solid tumors that express the epidermal growth factor receptor. J Clin Oncol 22:175-184, 2004

22. Trigo J, Hitt $R$, Koralewski $P$, et al: Cetux imab monotherapy is active in patients (pts) with platinum-refractory recurrent/metastatic squamous cell carcinoma of the head and neck (SCCHN): Results of a phase II study, Proc Am Soc Clin Oncol 23:487, 2004 (abstr 5502)

23. Xia W, Mullin RJ, Keith BR, et al: Antitumor activity of GW572016: A dual tyrosine kinase inhibitor blocks EGF activation of EGFR/ erbB2 and downstream Erk1/2 and AKT pathways. Oncogene 21:6255-6263, 2002

24. Rusnak DW, Lackey K, Affleck K, et al: The effects of the novel, reversible epidermal growth factor receptor/ErbB-2 tyrosine kinase inhibitor, GW572016, on the growth of human normal and tumor-derived cell lines in vitro and in vivo. $\mathrm{Mol}$ Cancer Ther 1:85-94, 2001

25. Bence AK, Anderson EB, Doukas MA, et al: Phase I pharmacokinetic studies evaluating single and multiple doses of oral GW572016, a dual EGFR-ErbB2 inhibitor, in healthy subjects. Invest New Drugs 23:39-49, 2005

26. Versola $M$, Burris $H A$, Jones $S$, et al: Clinical activity of GW572016 in EGF10003 in patients with solid tumors. Proc Am Soc Clin Oncol 23: 2004 (abstr 3047)

27. Spector NL, Xia W, Burris $H$, III, et al: Study of the biological effects of lapatinib, a reversible inhibitor of ErbB1 and ErbB2 tyrosine kinases, on tumor growth and survival pathways in patients with advanced malignancies. J Clin Oncol 23:1-11, 2005

28. Hsieh $S$, Tobien $T$, Koch $K$, et al: Increasing throughput of parallel on-line extraction liquid chromatography/electrospray ionization tandem mass spectrometry system for GLP quantitative bioanalysis in drug development. Rapid Commun Mass Spectrom 18:285-292, 2004

29. Therasse P, Arbuck SG, Eisenhauer EA, et al: New guidelines to evaluate the response to treatment in solid tumors. J Natl Cancer Inst 92:205-216, 2000

30. Minami H, Nakagawa K, Kawada K, et al: A phase I study of GW572016 in patients with solid tumors. Proc Am Soc Clin Oncol 22:14S, 2004 (abstr 3048)

31. Koch KM, Lee D, Jones $S$, et al: Pharmacokinetics of GW572016 in an ascending dose tolerability study of phase I cancer patients. Eur J Cancer 1:S169, 2003 (poster 559)

32. Wood ER, Truesdale AT, McDonald OB, et al: A unique structure for epidermal growth factor receptor bound to GW572016 (Lapatinib): Relationships among protein conformation, inhibitor off-rate, and receptor activity in tumor cells. Cancer Res 64:6652-6659, 2004

33. Baselga J, Rischin D, Ranson $M$, et al: Phase I safety, pharmacokinetic, and pharmacodynamic trial of ZD1839, a selective oral epidermal growth factor receptor tyrosine kinase inhibitor, in patients with five selected tumor types. J Clin Oncol 20:4292-4302, 2002

34. Hidalgo M, Siu LL, Nemunaitis J, et al: Phase I and pharmacologic study of OSI- 774, an epidermal growth factor receptor tyrosine kinase inhibitor, in patients with advanced solid malignancies. J Clin Oncol 19:3267-3279, 2001

35. Hoekstra $\mathrm{R}$, Dumez $H$, van Oosterom AT, et al: A phase I and pharmacological study of PKI166, an epidermal growth factor receptor (EGFR) tyrosine kinase inhibitor, administered orally in a two weeks on, two weeks off scheme to patients with advanced cancer. Proc Am Soc Clin Oncol 21, 2002 (abstr 340)

36. Dumez $H$, Hoekstra $R$, Eskens $F$, et al: A phase I and pharmacological study of PKI166, an epidermal growth factor receptor (EGFR) tyrosine kinase inhibitor, administered orally 3 times a week to patients with advanced cancer. Proc Am Soc Clin Oncol 21, 2002 (abstr 341)

37. Murren JR, Papadimitrakopoulou VA, Sizer $\mathrm{KC}$, et al: A phase I dose-escalating study to evaluate the biological activity and pharmacokinetics of PKI166, a novel tyrosine kinase inhibitor, in patients with advanced cancers. Proc Am Soc Clin Oncol 21, 2002 (abstr 377)

38. Garrison MA, Tolcher $A$, McCreery $H$, et al: A phase I and pharmacokinetic study of ora $\mathrm{Cl}-1033$, a pan-erbB tyrosine kinase inhibitor, given orally on days 1,8 , and 15 every 28 days to patients with solid tumors. Proc Am Soc Clin Oncol 20:72a, 2001 (abstr 283)

39. Nemunaitis JJ, Eiseman $C$, Cunningham $C$ et al: A phase I trial of $\mathrm{Cl}-1033$, a pan-erbB tyrosine kinase inhibitor, given daily for 14 days every 3 weeks, in patients with solid advanced tumors. Proc Am Soc Clin Oncol 22:243, 2003 (abstr 974)

40. Rinehart JJ, Wilding G, Willson J, et al: A phase I clinical and pharmacokinetic study of oral $\mathrm{Cl}-1033$, a pan-erbB tyrosine kinase inhibitor, in patients with advanced solid tumors. Proc Am Soc Clin Oncol 21:11a, 2002 (abstr 41)

41. Shin $D M$, Nemunaitis JJ, Zinner RG, et al: A phase I biomarker study of $\mathrm{Cl}-1033$, a novel pan-erbB tyrosine kinase inhibitor in patients with solid tumors. Proc Am Soc Clin Oncol 20:82a, 2001 (abstr 324)

42. Seidman A, Hudis C, Pierri MK, et al: Cardiac dysfunction in the trastuzumab clinical trials experience. J Clin Oncol 20:1215-1221, 2002

43. Suter TM, Cook-Burns N, Barton C: Cardiotoxicity associated with trastuzumab (Herceptin) therapy in the treatment of metastatic breast cancer. Breast 13:173-183, 2004 